\title{
Editorial: Introducing the ACM Journal on Educational Resources in Computing
}

\author{
(JERIC) http://www.acm.org/pubs/jeric/
}

ACM JERIC is an electronic publication providing access to high quality, archival resources suitable for support of computing education. Resources include scholarly articles with wide applicability and potential impact as well as multimedia and visualization works, laboratory materials, and other digital objects of practical use supporting learning in the computing field. These may support course presentation or informal learning, either locally or through distance education activities. They may be downloaded for use by trainers, teachers, students, or other learners.

JERIC resources support every aspect of computing education, whether the emphasis is on information, computation, hardware, software, theory, application, or newly emerging areas. JERIC defines computing broadly to include all aspects of disciplines including, but not limited to, computer science, computer engineering, information systems, information science, and software engineering. While the primary focus of JERIC is on materials for use in undergraduate learning, other levels of instruction are welcomed.

All materials selected for publication in JERIC will have demonstrated their significance in support of computing education and will have been judged of high value by qualified referees. JERIC works in conjunction with the Computing Science Teaching Center, http://www.cstc.org/, where work in progress or other less formally reviewed materials are accessible. Those submitting online to CSTC are invited to request review for JERIC if they feel the significance of their work warrants archival publication.

JERIC arose in part as a result of research supported by the ACM Education Board and the US National Science Foundation, through grants DUE-9752190: A Digital Library Based Computer Science Teaching Center (CSTC) and DUE-9752408: Curriculum Resources in Interactive Multimedia (CRIM). The proposal for JERIC was endorsed in spring 2000 by ACM SIGCSE, SIGMultimedia, and SIGIR. It was approved in summer 2000 by the ACM Publications Board. Ongoing activities with JERIC are supported in part by NSF-funded efforts to develop a National Science, Mathematics, Engineering, and Technology Education Digital Library (NSDL).

We hope that JERIC resources will support a broad international community of educators and learners. Please prepare, submit, nominate, review, or use JERIC resources. For instructions and further information, see the WWW site listed at the top of this document.

We welcome you to JERIC. We are pleased to have the greeting by guest editor Rachelle S. Heller, followed by the rest of the special issue that she has managed. Professor Heller is a leading authority on multimedia in education, and has been teaching a number of courses so that those in the 
computing field can learn about and through multimedia. She was co-PI on the NSF-funded CRIM project mentioned above, and is a founding member of the editorial board of JERIC. She has collected the articles and resources in this issue from an international conference in the area. We hope that you will learn from this special issue, and that it may help ensure that JERIC receives a steady stream of high-quality multimedia as well as other types of resources.

\author{
LiLlian N. CASSEL \\ Villanova University \\ Co-Editor-in-Chief \\ EDWARD A. Fox \\ Virginia Tech \\ Co-Editor-in-Chief
}

